\title{
El principio fundacional en la mitología y el ritual entre los tzotziles de San Andrés Larráinzar
}

\section{The Foundational Principle in the Tzotzil Mythology and Ritual of San Andrés Larráinzar}

\author{
José Alejos García \\ Centro de Estudios Mayas, Instituto de Investigaciones Filológicas, \\ Universidad Nacional Autónoma de México
}

\begin{abstract}
Resumen: El artículo examina la narrativa mitológica de fundación y su relación con la fiesta patronal de los tzotziles de San Andrés Larráinzar, argumentando que en este vínculo se enuncia un principio fundacional que incluye relaciones de parentesco, obligaciones morales, éticas y económicas entre la gente, el santo patrono y las entidades "dueñas" del territorio. En este sentido, se plantéa la actualidad de un principio mitológico de origen, que se renueva anualmente y que da sentido a las prácticas rituales al interior del pueblo.

El aporte del artículo consiste en el análisis de las complejas relaciones entre mitología y ritual, de los principios culturales fundamentales, de las ambivalencias cronotópicas y de los isomorfismos culturales, con base en datos etnográficos de San Andrés Larráinzar, principalmente.
\end{abstract}

Palabras clave: Tzotzil, mitología, ritual, fiesta patronal, San Andrés Larráinzar.

ABSTRACT: This article examines the mythological narrative of the town's foundation and its relation to the patronal festival among the Tzotzil people of San Andres Larrainzar, arguing the existence of a foundational principle that includes kinship relations and moral, ethical and economic obligations between the people, the patron saint and the entities who "own" the territory. Therefore, the argument poses the prevalence of a mythological principle of origin that is renewed every year and provides meaning to the town's ritual practices.

The contribution of this article resides in the analysis of the complex relations between myth and ritual, of the fundamental cultural principles, the chronotopical ambivalences, and the cultural isomorphisms, based mainly on the ethnographical data of San Andres Larrainzar.

KeYwords: Tzotzil, Mythology, Ritual, Patronal Festival, San Andres Larrainzar.

RECEPCIÓN: 9 de marzo de 2017.

ACEPTACIÓN: 25 de mayo de 2017.

DOI: 10.19130/iifl.ecm.2018.52.886. 


\section{Introducción}

El culto a los santos y las fiestas tradicionales han sido temas largamente estudiados por la antropología mesoamericana, y gracias a este interés se cuenta con una abundante documentación etnográfica, buena parte de la cual se inscribe en el campo de los estudios sobre ritual y religión. Asimismo, esos estudios han generado un importante corpus de narrativa de tradición oral, en particular de relatos mitológicos relativos a la migración y las hazañas del santo patrono ${ }^{1}$ previas a la fundación definitiva de su pueblo. ${ }^{2}$ En efecto, un recorrido somero por la bibliografía etnográfica permite identificar la presencia de un interesante género narrativo sobre los santos patronos, común entre los pueblos de los Altos de Chiapas y Guatemala. ${ }^{3}$

En este ensayo me interesa examinar justamente la relación que guarda el pueblo con su deidad patronal mediante una puesta en diálogo entre los mitos de fundación y el ritual de la fiesta patronal que se celebra cada año. La documentación consultada proviene de diversos estudios etnográficos entre los pueblos mayas de tierras altas, y el análisis está enfocado en el caso de San Andrés Larráinzar. $\mathrm{Mi}$ argumento central consiste en plantear a la fiesta patronal como un complejo ritual en el cual se actualiza un principio fundacional entre la comunidad, la deidad patronal y otras entidades del entorno; un principio que se encuentra enunciado en la narrativa mitológica y que los investigadores han señalado de diversas maneras, como un "lazo de parentesco", un "pacto", una "alianza", un "intercambio", un conjunto de principios morales y éticos (de gratitud, respeto, reconocimiento, cooperación, intercambio), entre los fieles y su santo patrono. Brevemente, la idea contenida en el relato mítico es que los nativos del pueblo son hijos del santo y que el pueblo existe gracias a los "trabajos" de su deidad, aquellos efectuados en un pasado remoto, pero cuyo patronazgo continúa en el presente.

Retomando la observación de Leach (1970) respecto al ritual como contraparte del mito, ${ }^{4}$ considero que la idea contenida en la fiesta patronal consiste justamente en manifestar, refrendar y honrar los lazos de la comunidad con su santo, y al

\footnotetext{
${ }^{1}$ En este ensayo empleo el término "santo", o "santo patrono" en un sentido genérico, solamente para facilitar la redacción, pero consciente de las distinciones concretas de género y número de los casos específicos. En muchos casos la deidad fundadora es referida como "padre-madre", es decir, como un ser dual, y en otros, como una dualidad entre un hermano mayor y otro menor.

2 "Pueblo" tiene aquí un sentido amplio, refiriéndose según el caso al poblado concreto, al territorio comprendido en el municipio, y también a la comunidad congregada en torno al culto del santo patrono, a la cual también me refiero como "los fieles" o simplemente como "la gente", reconociendo que en la realidad empírica no todas las personas que habitan el pueblo comparten las mismas ideas mitológicas y los mismos rituales.

${ }^{3}$ Por razones de espacio limito mis referencias sobre esta narrativa mitológica y sobre rituales de fiestas patronales extendidos particularmente a la región de los Altos de Chiapas y Guatemala. El lector interesado puede consultar la amplia documentación etnográfica disponible sobre el tema.

4 "Myth in my terminology, is the counterpart of ritual; myth implies ritual, ritual implies myth, they are one and the same... myth regarded as a statement in words "says" the same thing as ritual regarded as a statement in action" (Leach, 1970: 13-14).
} 
hacerlo efectúa lo mismo que el mito dice mediante la palabra. En este sentido, considero a esta fiesta como un ritual de refundación, cuyo "modelo" se encuentra enunciado en el relato mitológico. Otro aspecto interesante de esta relación entre mito y rito que me interesa examinar es la "irrupción" del espacio-tiempo mitológico durante la fiesta patronal, el retorno al momento arcano de la creación del pueblo, de los orígenes. ${ }^{5}$

¿Qué es entonces lo que se "funda" en la mitología y se actualiza en la fiesta? Mi propuesta es que tanto el mito como el ritual enuncian un principio fundacional que es el basamento de la comunidad y de su relación con las entidades extrahumanas. Advierto la existencia concreta de una diversidad de significados del ritual entre los participantes al interior de la fiesta patronal, incluso divergentes y conflictivos, pero también reconozco un plano de abstracción en la cultura misma en donde se concentran ciertos significados "simbólicos", de orden más general, que condensan ideas fundamentales de la cultura. Es allí donde se encuentra esta idea de la constitución de la comunidad, donde se confirma, se renueva, el vínculo parental y los principios morales y éticos (la gratitud, el reconocimiento, el compromiso, la fe, etcétera) entre el pueblo, su santo y las entidades del entorno.

En tal sentido, es importante aclarar que esta propuesta de estudio se ubica en determinado plano de abstracción de la cultura, reconociendo los enormes cambios ocurridos, históricos y contemporáneos, así como las diferencias de nivel entre los relatos mitológicos, el canon del ritual y la "realidad concreta", donde los fenómenos pueden aparecer alejados del modelo planteado e incluso contradecirlo, como podría ser el caso de los "fieles" o de la "comunidad"; la narrativa mitológica puede presentar versiones contradictorias, o haber desaparecido, o no ser vinculada por los pobladores a las actividades festivas, o pueden coexistir rituales nuevos, o suceder conflictos internos relacionados con el rechazo a "las tradiciones", etcétera. En mi opinión, estos fenómenos no contradicen necesariamente al modelo abstracto, sino que se ubican en un plano distinto de la vida cultural, siendo su distancia o cercanía puntos de referencia respecto del modelo mismo. ${ }^{6}$

A continuación presento un resumen etnográfico de la relación entre mitología y ritual en la fiesta patronal de San Andrés Larráinzar, para luego analizar sus componentes principales.

\section{El caso de San Andrés}

El pueblo tzotzil de San Andrés Larráinzar, en los Altos del estado de Chiapas, presenta para nuestros intereses una gran riqueza de material etnográfico e inter-

\footnotetext{
${ }^{5}$ Sobre el tema de la "irrupción” mitológica en el espacio-tiempo del ritual véase Alejos García, 2017.

${ }^{6}$ En todo caso, estas ambivalencias y contradicciones entre "el modelo y la praxis" presentan un interés para su estudio que aquí sólo puedo apuntar. Al respecto, véase la interesante discusión de Leach (1970: 4) sobre las diferencias entre modelo y realidad empírica.
} 
pretaciones acerca de su cultura. ${ }^{7}$ San Andrés forma parte la región cultural denominada "tzeltal-tzotzil" en los Altos de Chiapas, la cual ha sido objeto de una intensa y continuada investigación antropológica desde mediados del siglo xx, con una numerosa participación y contribuciones de instituciones e investigadores nacionales y extranjeros. Esta situación ha permitido generar una importante documentación etnográfica de los pueblos investigados, pero también ha abierto la posibilidad de comparar, de articular conocimientos, de sintetizar, y avanzar en el desarrollo de una etnología de los Altos de Chiapas. En particular, me interesa subrayar que en este esfuerzo de investigación se han privilegiado temas como la cosmovisión, el ritual y la religión, mismos que en la actualidad se encuentran en un intenso proceso de revisión crítica y reinterpretación. Así las cosas, este excepcional acervo etnológico y el ambiente de "efervescencia" en la investigación antropológica de esta área cultural posibilitan hacer planteamientos de un nivel de abstracción como el que aquí trato de desarrollar. La investigación etnográfica realizada en San Andrés cuenta ya con contribuciones muy importantes, entre las cuales quiero destacar las de William Holland $(1961,1963)$, Kasuyasu Ochiai (1983), Manuel Hidalgo (1985), Piero Gorza (2006a y 2006b), Juan López (2003) y Lucas Ruiz (2015), cuyos estudios he tomado como mis fuentes principales. ${ }^{8}$

Existen diversas versiones sobre la narrativa mitológica de la fundación del pueblo de San Andrés Larráinzar, algunas de las cuales han sido resumidas por Gorza (2006a, 2006b). En su conjunto, las versiones muestran variaciones importantes e incluso divergentes entre sí, siendo significativas la de la identidad del héroe fundador, quien en algunos casos aparece como san Andrés, o como el apóstol, a veces acompañado de un hermano menor y de otros santos hermanos, mientras que en otros es un personaje de la mitología maya, incluso asociado a la deidad solar (López, 2003; Ruiz, 2015), o como un "hombre kaxlan [blanco, forastero]". Otra diferencia consiste en el lugar de origen, a veces ubicado en el "oriente", y en ocasiones en el "norte" (Gorza, 2006b: 93), en Guatemala o en Simojovel (Hidalgo, 1985). También hay variaciones sobre los diversos lugares donde el santo y sus fieles se asientan temporalmente hasta la fundación del pueblo actual, las entidades con las que la deidad se enfrenta y "los trabajos" que debe hacer para lograr el control definitivo del territorio, construir su iglesia y fundar el pueblo.

A continuación realizo el resumen de una de estas variantes, publicada por López (2003) en un libro dedicado justamente a la "peregrinación de nuestros antepasados", y que me ha parecido de especial interés por tratarse de la obra de un nativo sanandresero, estudioso de su propia cultura y tradición, que documenta una nomenclatura y una cosmología tzotzil.

\footnotetext{
${ }^{7}$ Conservo la grafía tradicional del término "tzotzil" para estar acorde con la bibliografía citada, aunque estoy consciente del cambio de la letra " $\mathrm{z}$ " por la "s" en la convención linguiística contemporánea.

${ }^{8}$ En especial quiero manifestar mi agradecimiento al doctor Lucas Ruiz por los aportes de su propia investigación y por su valiosa asesoría en la elaboración de este trabajo, incluyendo las modificaciones efectuadas al texto en respuesta a los dictámentes académicos recibidos.
} 
La historia inicia con la introducción de dos personajes mitológicos, autores de "la creación", Baxakmen (8 Águila) y su hermano menor, Pukuj (san Miguel), quienes mantienen una relación ambivalente, de cooperación pero a la vez de rivalidad y conflicto. Ambos organizan una fiesta "en honor de la santa tierra", conduciendo a su gente a la cumbre del cerro "Ombligo de la tierra" (López, 2003: 47). Luego, Baxakmen emprende una migración durante la cual funda varios pueblos, construye "palacios" y gobierna, para luego continuar su camino en busca del lugar definitivo. Durante el recorrido llega a la montaña Junal, ${ }^{9}$ donde lee en su libro sagrado una profecía $^{10}$ que establecía la búsqueda de un sitio en el centro de la tierra para fundar el pueblo sagrado y celebrar allí la fiesta y cultivar el maíz. ${ }^{11}$ Junal es abandonado debido al frío y al ataque de jaguares que devoran a la gente, mismos que Baxakmen logra vencer gracias a sus poderes (López, 2003: 54).

La migración continúa, se fundan los pueblos de Kukalbits, Alkuch'en, Bachen y Latsbilton, donde se refugian para sobrevivir al diluvio. Posteriormente se funda el antiguo Sakamch'en [o Chanalum/Lugar de serpientes], donde Baxakmen otorga tierras a su gente para cultivar el maíz. En ese lugar expulsa a su hermano Pukuj, por dedicarse a tocar música y no trabajar en la construcción de su palacio. ${ }^{12}$ Asimismo, Baxakmen envía una "lluvia de agua caliente para frenar el crecimiento de los cerros en el centro de la santa tierra" (López, 2003: 68).

López González señala que durante la época colonial "San Andrés tomó la personalidad de Baxakmen", y continuó llevando a su gente en viaje, fundando diferentes pueblos [Iztacostoc, ${ }^{13}$ Amaytik] (López, 2003: 87). Una peste obliga a los sanandreseros a abandonar Amaytik, y, conducidos por "dos hermanos llamados Andrés", se trasladan a Chabajebal, pero como al hermano mayor no le gustaba

\footnotetext{
${ }^{9}$ Esta montaña se ubica en el municipio de Chalchihuitán. Agradezco a Lucas Ruiz por esta y las siguientes referencias a lugares de la región que aparecen en las notas de pie de página.

${ }^{10}$ Esta referencia al antiguo nombre del cerro como "Lugar del libro" parece indicar que la noción indígena de "libro" es anterior a la presencia hispana.

11 "Baxakmen, debajo de la sombre de un árbol y en la orilla de una laguna se detuvo; ahí leyó ante todos su libro sagrado, cuyo contenido eran profecías: que tenían que encontrar el centro de la santa tierra para edificar en él Chanalum (el pueblo de las sagradas serpientes), el pueblo de pueblos, el pueblo de todos, para poder seguir celebrando la fiesta de la santa tierra y cultivar en él el santo maíz como medio del sustento principal de la cultura y de la existencia. Por ese acto tan importante e inolvidable en la historia oral, aquel cerro fue denominado Junal, que en bats'ik'op significa "libro o papel" (López, 2003: 52)

12 "Desde aquellos años, Baxakmen invitó a su hermano menor para que juntos construyeran el palacio de Sakamch'en, pero cuando llegó el día de realizar los trabajos, el hermano menor se negó a reunir las piedras, a emparejar la tierra y a tomar las medidas del palacio./ Baxakmen se molestó con la actitud de su hermano, hasta que lo expulsó del territorio./ al adolescente[Pukuj: San Miguel] no le gustaba trabajar sino tocar música; por eso tuvo que irse a vivir a otro lugar al lado oriente [San Miguel]" (López, 2003: 66).

${ }^{13}$ Este pueblo también recibe el nombre de Sakamch'en o Chanalum.
} 
el frío, por las noches regresaba a la iglesia de Amaytik, a pesar de los esfuerzos de la gente por regresarlo. ${ }^{14}$

En aquel viaje fundaron el pueblo de Bach'en, que fue abandonado por falta de piedras para la construcción de la iglesia. Luego realizaron estancias temporales en Tentik y Tselejilo'; en este último sitio tuvieron un conflicto con los de Chamula, por lo que continuaron su viaje hasta llegar al "centro del mundo" en Chikinjobeltik. Allí encontraron un ángel ${ }^{15}$ llamado Chauk [rayo], dueño de una laguna, a quien san Andrés expulsó al cerro Junal, y como castigo recibió la maldición de una fiesta triste, con lluvia, así como la captura de dos de sus sirvientes, cuyas almas fueron tomadas por Chauk. Es así como san Andrés y su gente lograron establecerse por fin en "el centro de la santa tierra", edificar su iglesia y fundar su pueblo definitivo (López, 2003: 98-106). ${ }^{16}$

En sus resúmenes de los "cuentos" de fundación del pueblo, Gorza (2006a) destaca a san Andrés como el héroe que guía el viaje y funda el pueblo, luego de vencer a un ángel, dueño de la laguna encantada, cuya niebla se transformaba en un toro que mataba a la gente, y a quien el santo logra vencer. Luego de engañar al ángel y enviar la laguna a otro lugar, san Andrés funda su pueblo, pero como castigo recibe lluvia en su fiesta y la pérdida de dos mensajeros. ${ }^{17}$ Asimismo, se

14 “... Entonces lo volvían a traer, pero volvía a desaparecer milagrosamente en las noches; la última vez que lo fueron a traer dicen que lo trajeron cargado de un mecapal y, como pesaba mucho, hasta parecía estar sembrado como un árbol... la imagen de San Andrés apóstol regresó a vivir en medio de su casa, sentado en el altar de su iglesia..." (López, 2003: 94).

${ }^{15}$ El autor emplea este nombre, aunque los etnógrafos prefieren la grafía anjel "porque no se refiere al ángel cristiano" (Lucas Ruiz, comunicación personal).

16 "La laguna colorada estaba ocupada por un ángel de la cual era el dueño; San Andrés, como le gustó aquel valle, le pidió que le permitiera vivir en aquel sitio montañoso, pero el ángel no quería ceder su propiedad, por eso tuvieron que discutir fuertemente. / San Andrés, por su insistencia, logró expulsar al ángel $[$ Chauk]... muy enojado le gritó... Tú, San Andrés, me viniste a quitar mi tierra... pero te advierto que las fiestas que vas a celebrar no pasarán alegres, porque para ese día vendrán muchas lluvias, tormentas, neblinas, vientos y mal tiempo. / El señor Chauk aceptó la permuta y pasó a vivir en Muk'tajo', otra laguna que se localiza al sur... como el ángel era malo, no les permitía pasar a las personas cerca de su territorio" (López, 2003: 105).

"Dicen que el ángel aceptó la permuta de la laguna pero que aparte de la amenaza de lluvia llevó dos almas de los mejores sirvientes de San Andrés... Por eso, anteriormente al alférez de San Andrés, que lo ejerce un exalcalde tradicional, se le sacrificaba mucho en cada fiesta; esto se hacía durante un mes antes de la celebración en memoria de los dos muchachos que entregaron sus vidas para darles tierra, y para que no se cumpliera la amenaza..." (López, 2003: 106).

17 "Los más viejitos cuentan que san Andresito venía del Norte, de Huitiupán... y pasó por Simojovel... Se dice que allí donde está la iglesia era una laguna, pero san Andrés la mandó allá donde ahora está la escuela secundaria. La laguna estaba encantada y no podía acercarse nadie. Había una neblina que se convertía en un toro. Tampoco le convenía a san Andrés ver morir a su gente. Por esto obligó a la laguna a trasladarse al cerro Junal. Según cuentan los viejitos, allí continúa viviendo el dueño de la laguna que se convierte en toro y mata a quien pasa. Por venganza, el día de la fiesta de san Andrés, llueve siempre" (Gorza, 2006a: 50-51).

“... También allí el santo no agradeció el lugar, faltaba espacio para los borregos y el área era demasiado pedregosa para los cultivos, por esta razón se desplazó donde ahora hay una iglesia y una vez hubo allí una laguna. Para apoderarse del sitio, san Andrés tuvo que luchar con un toro, engañar al ángel, dueño de la charca y transferir el lago a diferentes lugares. Después construyó la iglesia, la 
menciona a dos hermanas menores, Magdalena y Marta, patronas de pueblos cercanos, con quienes san Andrés se visita recíprocamente durante sus respectivas fiestas. ${ }^{18}$

Por su parte, en su recopilación bilingüie de la tradición oral de Larráinzar, Hidalgo (1985) registra otras versiones de la fundación del pueblo, en las que se establece que Vaxakmen ("todo poderoso", "sostenedor de los ocho pilares del mundo") es el "padre", creador del "valle y los cerros", "dueño de las cuevas" y creador de la tierra para hacerla habitable a los humanos" (Hidalgo, 1985: 74, 76). Su origen se ubica en el cielo, pero también en Guatemala; luego de viajar llega a su lugar definitivo a "sembrar y construir su casa", donde gana un "pleito" con una laguna y un árbol de ocote que se oponían a la fundación del pueblo. Con la primera establece un "pacto", según el cual ella será su mensajero, y la lluvia lo visitará en su fiesta, "por eso, a causa del pacto que hay entre ellos, todos los años llueve bastante el día de la fiesta del santo apóstol” (Hidalgo, 1985: 94).

Otra versión registrada por Hidalgo cuenta que san Andrés llegó con los antepasados desde Simojovel a Ba Ch'en, un lugar muy chico y peligroso, por lo que se mudaron a Tentik; pero tampoco les gustó, así llegaron a Sak Ajtik, sitio sagrado con buenas tierras y agua en abundancia. Pero allí habitaba un ángel, dueño de la tierra y de una laguna, quien, enojado, tomó el alma de dos mensajeros y les advirtió que la fiesta siempre sería con lluvia, viento y mal tiempo. "El ángel se fue a vivir a Kukal Vitz, y así nuestros ancestros pudieron establecerse. Luego construyeron la iglesia de nuestro santo Señor San Andrés, hermanito de nuestro padre sol, y desde entonces celebramos aquí sus santas fiestas" (Hidalgo, 1985: 96-100).

Por su interés para esta discusión, incluyo un relato de fundación del pueblo tzotzil de Simojovel recopilado por Toledo Tello:

Cuando llegaron los ancianos, los antiguos, preguntaron por un ojo de agua [para ver] si podían vivir ahí o no podían vivir. Por medio del sueño les dijeron que no podían... dijeron que el ojo de agua era fuerte, que tiene su espíritu y mejor hay que salir, hay que buscar otro lugar... Llegaron a otro lugar, hablaron con otro que se llama jocoxton es una piedra, hablaron otra vez por medio del espíritu y contestó

casa del alma, ch'ul na. Sin embargo, la ira del ángel continúa manifestándose con la recurrente lluvia que cae en el día de la fiesta patronal" (Gorza, 2006a: 51).

"Mis hijos no caminarían aquí, no celebrarían fiestas [dijo san Andrés]... habló con el dueño del río... Brazo Velludo... se vengó cada año, enviando en el día del santo patrono la lluvia. La laguna se secó y el apóstol pudo construir la iglesia" (Gorza, 2006a: 52).

"El apóstol tuvo que enfrentarse con el ángel de la laguna que no quería dejar su espacio. El santo envió dos varones a pedir permiso, y el ángel pidió las almas de los mejores varones; san Andrés rechazó la propuesta y el ángel hizo enfermar a los 'dos mensajeros', 'los dos hermanos' y se llevó sus almas. Además, prometió enviar lluvia en los días de la fiesta mayor" (Gorza, 2006a: 53).

18 "El apóstol tuvo dos hermanas menores: santa María Magdalena y santa Marta. Cuando la casa de san Andrés fue construida, las dos hermanas, que habían salido por ocho días, regresaron llevando frutas. Por esto ahora las dos hermanas viven cerca de san Andrés y los poblados se pueden ver directamente. En las fiestas importantes los hermanos se visitan recíprocamente" (Gorza, 2006a: 52). 
por medio de la piedra y dijo: "está bien si quieren vivir aquí, solo tengo calor y frío y si ustedes aguantan, entonces pueden vivir aquí”. Entonces sí les gustó, porque aquí una parte es tierra caliente, una parte un poco fría... llegamos a entender que esta madre tierra es muy buena. Así llegaron los ancianos y trajeron a su apóstol que se llama san Antonio ... (Toledo, 2006: 167-168)

\section{Identidad y alteridad}

El espejo del santo se refleja en el del alférez, y ambos reflejan

a la comunidad de los fieles

(Gorza, 2006a: 95)

De entrada, es importante destacar el carácter de persona que presentan todos los personajes de la narrativa, incluyendo a las piedras, el rayo, los jaguares, las serpientes, etcétera. Las relaciones que el santo establece con todas estas entidades son sociales, si bien en algunos casos conflictivas, en donde cada quien ejerce su capacidad de agencia, y en donde se muestra que entre todos los personajes se comparte una "cultura”, distinguiéndose entre ellos más bien por su apariencia, es decir, por su "naturaleza”, para emplear la terminología ontologista.

Otro aspecto notable es la complejidad y ambivalencia respecto de las identidades de los personajes, particularmente la del héroe fundador, quien aparece asociado a la deidad solar creadora del cosmos, Baxakmen, ${ }^{19}$ pero asimismo a la deidad que guía a su gente por la migración hasta el “centro de la tierra”. López González señala cómo la Colonia produjo la transformación de Baxakmen en san Andrés, y de Pukuj, su hermano menor, ${ }^{20}$ en san Miguel, ${ }^{21}$ santo de los músicos, con quien el héroe fundador mantiene relaciones de cooperación pero también de rivalidad. Cabe mencionar que en la actualidad es común encontrar, por un lado, una disociación entre Pukuj y san Miguel, y, por otro, una asociación de Pukuj con el "diablo" de la mitología cristiana. ${ }^{22}$ Este fenómeno de los héroes dobles se reproduce más adelante en las figuras de los dos hermanos san Andrés, el mayor y el menor, que se encuentran actualmente en la iglesia de Larráinzar. $^{23}$

\footnotetext{
19 “Los santos católicos [son] metamorfosis del Sol y la Luna” (Ochiai, 2006: 149). Véase también Ruiz (2015).

20 Posteriormente, Pukuj va a ser identificado además con el diablo cristiano.

21 "San Andrés tomó la personalidad de Baxakmen... él se encargó de guiar también a la gente en los viajes que realizaron durante la época colonial” (López, 2003: 87). Asimismo, el autor refiere a la transformación de Pukuj: "Algunos sanandreseros todavía se acuerdan del antiguo personaje [Pukuj] sólo que en la época colonial se transformó en la imagen de San Miguel” (López, 2003: 67, n.2).

${ }^{22}$ Estas transformaciones en la identidad de los personajes mitológicos remiten al problema del cambio cultural, a las alteraciones en la construcción de la memoria colectiva operadas como resultado del proceso de colonización ideológica.

23 "Cada santo tiene su doble, según el principio normativo del hermano mayor, bankilal, y del menor, ytzinal” (Gorza, 2006a: 56-57).
} 
A esto hay que agregar las relaciones de parentesco del santo: es padre de la gente del pueblo y hermano mayor de Marta y Magdalena, patronas de los pueblos vecinos. San Andrés aparece también como un hermano de Cristo, apóstol, santo cristiano, "blanco", "extranjero". Gorza enfatiza la ambigua identidad del santo, señalando, por un lado, su carácter de divinidad solar indígena, padre del pueblo y héroe fundador, $\mathrm{y}$, por el otro, su carácter de extranjero.

San Andrés es un ser del cielo, hermano de Cristo, un apóstol, pero es también padre del pueblo y héroe fundador. Es un hombre-dios que comparte en su pertenecer al cielo aspectos del astro solar... por supuesto, es un blanco, que viene de otra tierra. No hay en el panteón santos indígenas, pero todos tienen historias que radican en la aldea y además se someten a la jererquía del mayor y del menor... cada santo tiene su doble, según el principio normativo del hermano mayor, bankilal, y del menor, ytzinal (Gorza, 2006a: 56-57).

En el mismo sentido encontramos la discusión de Pitarch acerca del santo patrono del pueblo tzeltal de Cancuc, en la que muestra la paradoja respecto a la alteridad europea como constitutiva de la identidad indígena:

Las imágenes de los santos que se encuentran en la iglesia constituyen una inversión, no obstante parcial, de la representación tzeltal de un ser humano en su vertiente exterior... cuando un indígena de Cancuc se sitúa frente a un santo está viendo su propio interior. Esta relación recíproca entre hombres y santos se encuentra expresada de una forma sensible en los textos de las oraciones, cuando el rezador se dirige al santo mediante la fórmula: "devuélveme tu viva mirada", "devuélveme tu vivo rostro". Esto es, se pide a la imagen que se encuentra enfrente que devuelva el reflejo de uno mismo - la mirada, el rostro — una vez que ha atravesado el "lado otro”, sagrado. Quizás por ello los santos de las iglesias tzotziles portan un espejo a la altura del pecho, donde se encuentra el corazón (Pitarch, 2006: 86- 87).

Otros personajes con identidades ambivalentes son los "dueños" de los lugares donde el santo intenta fundar su pueblo. Cada lugar aparece poseído por un "dueño", a quien el santo debe pedir una suerte de permiso de residencia (un cerro, un ojo de agua, el rayo, una piedra, y serpientes o jaguares como aliados), si no quiere entrar en un "pleito" por la posesión del lugar, como ocurre en el asentamiento definitivo. Unas versiones identifican a este "dueño" con la deidad de la lluvia (Chauk), con "Brazo Velludo" o con una "laguna”, acompañados de aliados serpientes, o de un árbol de ocote, mientras otras versiones lo identifican como un "ángel”, que tiene como aliado a un toro. En todo caso, estas entidades aparecen como "dueñas", o aliadas de éstas, con quienes el santo debe en definitiva establecer un acuerdo, un "pacto", a fin de poder establecerse en el lugar.

Por último, se encuentra también la cuestión acerca de la identidad de los nativos del pueblo, los sanandreseros, quienes en algunas versiones no son mencionados explícitamente, pero cuya presencia se encuentra sobreentendida. ${ }^{24}$

${ }^{24}$ Véase Pitarch (2006: 79-80). 
En todo caso, son ellos los hijos del santo patrono, son "la gente" a quien éste protege, la "comunidad" a quien guía en su migración, por quienes la deidad lucha y negocia los acuerdos que permiten la fundación del pueblo, y, a fin de cuentas, son ellos quienes tiene la responsabilidad de reconocer al santo como su padre, de alimentarlo y rendirle culto, de continuar con las obligaciones establecidas con la entidades al momento de la fundación. Aquellos que acompañaron al santo en la migración también son nombrados "los antepasados", los ancianos, e incluso las padres-madres del pueblo, con quienes los nativos del pueblo mantienen no sólo relaciones de parentesco, sino obligaciones morales originadas al momento mismo de la fundación, entre las cuales se encuentra obviamente alimentar al santo, reconocer a los "dueños" del lugar y festejar al santo en su cumpleaños. ${ }^{25}$ Estos deberes aparecen sobreentendidos, ya que no suelen mencionarse de manera explícita. ${ }^{26}$

\section{La migración ${ }^{27}$}

El tema de la migración del santo y de su gente ocupa un lugar central y abarca el mayor espacio al interior de la narrativa. Allí se concentran las hazañas, las rivalidades, los conflictos, los acuerdos y las fundaciones temporales que el héroe lleva a cabo a lo largo de su recorrido. Destaca, primero, la ambivalencia respecto al lugar de inicio de la migración, en algunos relatos se trata de una ubicación abstracta, como el "oriente", "el norte" o "el poniente", mientras en otros la referencia es a un lugar específico, como Huitiupán, Simojovel o Guatemala. Luego, destacan los asentamientos temporales que funda el héroe, su nomenclatura, sus características geográficas, climáticas, así como las construcciones realizadas (la casa, el palacio o la iglesia). En todo caso, para nuestro argumento, lo más importante son las hazañas del santo a lo largo de su recorrido, pues en ellas se ponen de manifiesto "los trabajos", las "tribulaciones", los "peligros", las "luchas", "las conquistas del territorio", los "pactos", que tuvo que superar y efectuar con el fin de lograr el bienestar de su gente y la fundación de su pueblo. ${ }^{28}$ Este aspecto marca justamente las razones por las cuales los "hijos del santo" adquieren una serie de responsabilidades respecto al santo y a los "dueños".

\footnotetext{
${ }^{25}$ La narrativa deja en claro que los sanandreseros no son los dueños del lugar, y eso establece la obligación tanto de ese reconocimiento como de "ofrendar" a los legítimos dueños.

${ }^{26}$ Sobre el concepto de los sobreentendidos en la cultura, véase Voloshinov (1997) y Alejos García (2012).

${ }^{27}$ No hay acuerdo respecto al nombre que se ha dado a este viaje del santo, algunos lo llaman una peregrinación (López, Pitarch), otros lo denominan un viaje liminal (Gorza), o un viaje invernal o errático (Ochiai). Aquí prefiero llamarlo migración, atendiendo a su finalidad de cambiar de lugar de residencia.

${ }^{28}$ Gorza considera que esta narrativa mítica de viaje habla de un ritual de pasaje que otorga la legitimidad de habitar un lugar específico. "El fundador es un santo a quien correspondió venir de lejos para conquistar el derecho a habitar" (2006b: 94).
} 
Otro aspecto relevante es la semejanza de estos relatos de viaje con aquellos relatos mitológicos de migraciones de otros pueblos mesoamericanos, como el de los quiché, descrito en el Popol Vuh, o el de los mexica en el centro de México. Esta semejanza permite suponer la existencia de un género narrativo específico, compartido por culturas mesoamericanas ${ }^{29}$ un cronotopo mitológico de la migración, ${ }^{30}$ para ponerlo en términos de Bajtín (1981).

En tal sentido, son interesantes las observaciones de Pitarch, quien, si bien considera que la narrativa sobre los santos es muy escasa, ${ }^{31}$ resalta el tema de lo que él llama "peregrinaciones", como en el caso de Cancuc. ${ }^{32}$ El autor relaciona esta migración de los santos con aquella narrada en el Popol Vuh, efectuada por los quichés desde Tulán, señalando como diferencia que en el relato tzeltal no aparecen seres humanos, aunque estos se encuentran sobreentendios en la narración. En ambos casos, los hechos narrados parecen ocurrir antes del surgimiento del sol. "Los antepasados cancuqueros están en realidad implícitos, sobreentendidos, en la narración" (Pitarch, 2006: 79-80). Esta similitud ya había sido discutida por Ochiai (1983), en su estudio estructural entre el Popol Vuh y los relatos de fundación de san Andrés. Este autor se refiere a la migración como un "viaje invernal" y "errático", encontrando una similitud estructural entre ambas narrativas, a las que asocia con nexos políticos existentes entre los pueblos de los altos de Guatemala y Chiapas en la época anterior a la conquista.

\section{La fiesta patronal}

Las razones por las cuales se debe celebrar la fiesta del santo patrono no se enuncian explícitamente en la narrativa, son un motivo que puede considerarse

\footnotetext{
${ }^{29}$ Véase el estudio de Vapnarsky acerca del tema mitológico y ritual de lo que denomina el "recorrido" de la deidad fundadora para la cultura maya yucateca, vinculándolo a las nociones de espacio, tiempo e identidad del grupo: "la imagen de un recorrido juega un papel estructurante: el recorrido de un territorio constituye el fundamento de las obras de creación” (2003: 368).

30 Véase el estudio de Navarrete (2004) sobre los cronotopos históricos mesoamericanos.

31 "Las narraciones donde los santos son protagonistas del relato son llamativamente escasas... en Cancuc prácticamente ningún santo posee una identidad narrativa, con excepción de san Juan, el santo patrono". Este es un relato en que se narra la ayuda que san Juan presta a sus hermanos, cuyos pueblos estaban amenazados por una inundación del río Grijalva (Pitarch, 2006: 78).

32 "Los santos vivían en otro lugar, en un lugar en el oriente. Acordaron entonces repartirse por el mundo y fundar pueblos. San Juan decidió dirigirse al centro del mundo (Cancuc), mientras que otros santos eligieron pueblos como Chamula... Durante algunos años san Juan permaneció en Bachajón... después decidió emigrar hasta donde se encuentra en la actualidad: Cancuc... otros santos que acompañaron a los actuales santos patronos no encontraron un lugar y tuvieron que convertirse en los dueños de los cerros" (Pitarch, 2006: 79).

"El segundo relato sucede en un tiempo aun más remoto... narra la peregrinación de los santos desde el Oriente hasta el lugar donde se encuentran en la actualidad... san Juan decidió dirigirse al centro de mundo (Cancuc)... entonces también se asentaron los santos patronos de Chamula, Tenejapa, Oxchuc y de los demás pueblos. Otros 'santos' que acompañaron a los actuales santos patronos no encontraron un lugar y tuvieron que convertirse en los dueños de los cerros" (Pitarch, 2006: 79)
} 
otro de los grandes sobreentendidos del género narrativo, lo cual resulta paradógico, si se considera que esta fiesta conforma el ritual que sintetiza y actualiza la narrativa mitológica de la fundación del pueblo. Sin embargo, sí encontramos algunas menciones a la fiesta que resultan reveladoras.

Por un lado, en una de las versiones recopilada por López González (2003: 47) se menciona una "fiesta grande" en honor a "la santa tierra" que los héroes Baxakmen y Pukuj realizan junto a la gente "hecha de maíz", en la cumbre del cerro "Ombligo de la tierra", luego de la creación del cosmos, y que marca el inicio de la migración que concluirá con la fundación del pueblo de san Andrés. En este acontecimiento destaca la creación de la bebida por parte de Baxakmen, y el sentido de su consumo ritual, así como su influencia embriagante debido a la adición por parte de Pukuj de sus orines. "En un instante comenzaron a alterarse, comenzó la bulla, perdieron la pena, el miedo de hablar y el equilibrio; la fiesta se alegró, sus instrumentos musicales tuvieron sonido y volumen, y hasta danzaron aquellos hombres cubiertos de piel de jaguares" (López, 2003: 50). Este ambiente de alegría, de música y baile, de abundancia y embriaguez, es justamente el que se busca lograr en las fiestas actuales, y contrasta marcadamente con el sentido "serio", "ceremonial", de la fiesta desde la perspectiva de Baxakmen. ${ }^{33}$

Por otro lado, en prácticamente todas las versiones, la mención a la fiesta ocurre al final de la narrativa, en donde se explica la lluvia y el mal tiempo que caracteriza la fiesta de san Andrés, como un castigo o venganza de parte del rayo (o ángel) por haber sido desterrado junto a su laguna y las serpientes, cuando el santo estableció su "casa" en ese lugar. Destaca en este sentido la serie de estrictas abstinencias reportadas en la etnografía, practicadas por los alféreces encargados de la fiesta, a fin de conjurar el maleficio del "dueño" del lugar y conseguir un buen tiempo, sin lluvia, que asegure la alegría.

...Dicen que el ángel aceptó la permuta de la laguna pero que aparte de la amenaza de lluvia llevó dos almas de los mejores sirvientes de San Andrés... Por eso, anteriormente al alférez de San Andrés, que lo ejerce un exalcalde tradicional, se le sacrificaba mucho en cada fiesta; esto se hacía durante un mes antes de la celebración en memoria de los dos muchachos que entregaron sus vidas para darles tierra, y para que no se cumpliera la amenaza. Si el alférez resultaba ser responsable era cruelmente latigado en la iglesia para purificarle su cuerpo. El sacrificio o purificación consistía en no trabajar, abstención sexual con la pareja, no bañarse ni lavar la ropa y la cara, no realizar compras, no caminar, estar en constante ayuno, etcétera. Esto lo llevaban a efecto los alférez para que en la fiesta grande no lloviera y lo pasaran alegre (López, 2003: 106-108).

Esta serie de abstinencias marca justamente la conexión entre el relato mítico de fundación y la práctica ritual que ocurre durante la fiesta. Gorza destaca el

\footnotetext{
${ }^{33}$ Este punto es importante, pues marca en la narrativa misma la tensión existente entre el "modelo" y la "realidad", entre el discurso oficial y el discurso popular, en términos de Bajtín.
} 
sentido de esta práctica como un procedimiento ritual para revertir el conjuro, la cual se encuentra documentada desde la época colonial. Al respecto, el autor refiere un caso de hechicería de 1778 , que se describe como un complejo culto a la cueva Sacamch'en, ${ }^{34}$ practicado por las mismas autoridades de la comunidad (2006a: 60-64). Esta documentación incluye un rezo que se efectuaba en la cueva, que permite a Gorza considerar que allí se practicaban las ceremonias en honor al santo patrón: "ayúdame divino espíritu, Santo Capitán, para que en los días de mi fiesta haga buen tiempo". El autor subraya la continuidad de ciertas prácticas rituales del presente etnográfico: "En el mes que precede a la fiesta del apóstol, los alféreces tienen que respetar el ayuno, ir a las iglesias a pedir a los dioses que no llueva, hincarse y azotarse públicamente" (Gorza, 2006a: 64).

Gorza también observa una importante relación "especular" entre la narrativa de fundación con las ceremonias anuales, en donde se rememoran el recorrido del santo, ya sea el recorrido de los distantes lugares de origen a la tierra legítima, o de esta última a nuevos espacios: ${ }^{35}$ "En efecto, la procesión el día de la fiesta grande va de la casa de los alféreces al templo y viceversa, mientras los capitanetik recorren a caballo los perímetros sagrado del pueblo, deteniéndose en las cruces de encuentro, de protección o separación de los espacios restantes" (Gorza, 2006b: 95).

Lo anterior nos permite constatar una relación dialógica entre la narrativa mitológica y el ritual de la fiesta patronal que se despliega en varios planos. Primero, la fiesta es una "respuesta" del pueblo dirigida en un doble sentido: por un lado, al "rayo" para disipar el conjuro, y, por el otro, a los beneficios recibidos de parte del santo patrono, como una reafirmación de la continuidad del intercambio. Segundo, el fenómeno "especular" al que se refiere Gorza respecto de los recorridos del santo y de los alféreces durante la fiesta muestra justamente al relato mítico como el "modelo" de fondo. Por último, las abstinencias vistas como actos rituales destinados a cambiar el "castigo" y gozar así de un buen clima durante la fiesta son igualmente un enunciado que responde al conjuro del dueño de la laguna.

En mi opinión, esta doble tensión que se marca en la narrativa respecto de la fiesta apunta hacia la percepción de dos fuerzas divergentes que operan al interior de la cultura: una centrípeta, en donde el relato mítico establece el canon normativo de la fiesta, personificada por Baxakmen, y la otra centrífuga, personificada por Pukuj, quien está en abierta rivalidad con su hermano mayor y que representa las tendencias opuestas presentes en la fiesta misma, algunas de las cuales podríamos considerar como "profanas". Estas mismas fuerzas se harían presentes en la celebración anual de la fiesta patronal. Por otro lado, tenemos

\footnotetext{
34 "Lugar de vida, lugar de partida, lugar de llegada. Por supuesto esa [cueva] fue casa del alma, casa de un espíritu de la tierra y cabecera del municipio" (2006a: 62).

${ }^{35} \mathrm{Al}$ respecto, véase el estudio de Vapnarksy (2003) sobre los circuitos rituales de apropiación del espacio entre los mayas yucatecos.
} 
aquella tensión entre Rayo y san Andrés, producto de la apropiación del territorio del primero por el segundo, y que da por resultado "el mal clima", prescrito en el relato, y los esfuerzos por exorcizar el conjuro mediante el ritual. Al mal clima determinado por el relato mítico se opone la acción humana orientada a revertir el sufrimiento por la alegría. Volveremos a este punto más adelante.

\section{El principio fundacional}

En Momostenango, un brujo dijo que "el [Dios] Mundo es como una madre que se sacrifica dando a sus hijos lo que tiene (cosechas, animales, agua, etcétera); pero le cuesta darlo todo; le causa dolores y molestias, y por esa razón el hombre tiene que ser como hijo agradecido para no ser castigado: debe querer a Dios y al Mundo, como se quiere al padre y a la madre. En resumen, a la tierra, al Mundo, hay que pagar tributo, porque de él se recibe la vida y él recibe a las personas al morir" (Anónimo, Guatemala Indígena, 1963: 84).

Las palabras de aquel "brujo" quiché resumen el principio que se encuentra implícito en la narrativa de fundación de San Andrés, y que se lleva a la práctica durante la fiesta patronal. Los hijos del santo deben ser "agradecidos", reconociendo los "dolores y molestias" de sus progenitores para conseguir el terreno, para alimentarlos, deben "pagar tributo" por la vida recibida, y por el cuidado que recibirán al morir.

En su detallado estudio etnográfico sobre la fiesta en San Andrés Larráinzar, Ochiai $(1985,2006)$ destaca las relaciones de parentesco entre los santos que se ponen de manifiesto en la narrativa mitológica, así como en los actos de los rituales públicos durante la fiesta patronal. Se registra la relación de parentesco entre san Andrés y sus hermanos, manifiesta en las visitas mutuas durante sus respectivas fiestas: ${ }^{36}$ "el intercambio de santos es la ocasión donde se proclama la relación mitológica de hermandad entre los santos patronos de las comunidades vecinas" (2006: 101). Sin embargo, en un estudio previo, Ochiai reconoce el parentesco de hermandad entre los santos, pero niega que en la narrativa de san Andrés se establezca un nexo de parentesco entre la deidad y la gente, considerándolo una "confusión" (Ochiai, 1983: 336), lo cual, como hemos visto, parece no ser el caso. Hoy en día, los fieles de san Andrés se reconocen claramente como hijos del apóstol. ${ }^{37}$

Por su parte, en su estudio de San Andrés Larráinzar, Gorza identifica símbolos fundamentales contenidos en la narrativa sobre el santo patrono. Considera que en los relatos se encuentra la descripción de un rito de pasaje, un ritual de iniciación (Gorza, 2006b: 94), que empieza con un viaje liminal, continúa con una

\footnotetext{
36 "Un mito andresero narra cómo los santos hermanos de las comunidades cercanas iniciaron sus intercambios de visitas durante las ocasiones festivas en un pasado mítico" (Ochiai, 2006: 149-150).

${ }^{37}$ Lucas Ruiz, comunicación personal.
} 
lucha, la resolución del conflicto y concluye con la fundación del pueblo. ${ }^{38}$ Plantea la construcción de la iglesia como el momento en que se establece un "pacto social" entre los hombres y las deidades que debe ser actualizado de modo constante (Gorza, 2006a: 73). En tal sentido, señala que "los andreseros... la gente del pueblo se identifica como hija del apóstol, un santo que, independientemente de la tradición hagiográfica, vino de tierras cercanas" (Gorza, 2006a: 50), y que por lo tanto las fiestas a los santos "representan el momento de refundación de la comunidad" (Gorza, 2006a: 18). La fiesta evoca el tiempo de la creación, pero también el miedo al desorden y al cataclismo, que deben ser conjurados mediante la celebración al santo patrón. ${ }^{39}$ Según Gorza, "la fiesta es un hecho cosmogónico... la fiesta no remite sólo al presente sino también a la obra primigenia de construcción del mundo... el pasado regresa y puede hablar a través de la repetición de normas fijas" (Gorza, 2006a: 94-95).

En el mismo sentido, en su análisis de la identidad de los santos tzeltales, Pitarch afirma la existencia de "una relación recíproca por necesidad" entre los santos y los hombres, ya que los primeros necesitan ser alimentados:

Los cuerpos de los santos deben ser alimentados por los humanos, dado que son incapaces de procurarse alimento por sí mismos... necesitan ser alimentados en los rituales. Entre santos y hombres existe una relación recíproca por necesidad. Su dieta incluye preferentemente velas, incienso de copal, tabaco y aguardiente de caña u otro licor. En realidad no consumen propiamente esos productos, sino el humo del incienso, el aroma de la vela, el vapor etílico del aguardiente; esto es, aquello que es lo ch'ul, lo sagrado, lo "otro" de estas sustancias (Pitarch, 2006: 76).

Lo anterior nos muestra que esta relación de parentesco genera una relación de intercambio "económica" entre la comunidad y la deidad patronal. Si ésta proporcionó en un tiempo-espacio mitológico los soportes materiales para la existencia, sus hijos tienen, en el aquí y ahora, el deber de responder en el mismo sentido, alimentando al santo. La comunidad recibe el compromiso de honrar el "pacto" establecido entre su patrono y las entidades del entorno, dueñas legítimas del lugar que ocupa su pueblo. Así pues, nos encontramos con un complejo principio que incluye relaciones de parentesco, económicas, éticas y morales

\footnotetext{
38 "En todas las etapas intermedias, las tierras rechazan al Apóstol y, finalmente, en la última se desarrolla la lucha para legitimar la posesión... se necesia un sacrificio, una donación... los relatos resumidos narran un rito de pasaje, un ceremonial de iniciación. Se abandonan las tierras, empieza un viaje liminal que termina con una lucha, se resuelve el conflicto con la formación de la comunidad nueva. El 'pacto social' se realiza con la construcción del templo y sólo a partir de ese momento se fijan las fronteras y se establecen relaciones con los vecinos. El tiempo fracturado de los dioses se abre como tiempo de los hombres" (Gorza, 2006a: 55-56). "Carmagnani habla de cómo los dioses ceden un territorio a los hombres a cambio de un pacto de alianza y exclusión. Los límites separan a los que pueden residir de los que se quedan afuera" (Gorza, 2006a: 101).

39 "El último día de la fiesta se llama muk'ta k'in. K'in quiere decir fiesta y envía al kinh de los antiguos mayas, que significa sol y día... también los actuales descendientes de los mayas conservan en su habla la polisemia antigua: k’in es la fiesta, el día y el sol” (Gorza, 2006a: 83-84).
} 
entre la comunidad, la deidad patronal y las entidades del entorno, cuya lógica la resume el intercambio. En este sentido, cabe recordar el estudio etnográfico de Millán sobre los grupos étnicos de Oaxaca (1993), enfocado al análisis de las ceremonias y fiestas de los pueblos, donde concluye con una reflexión según la cual "la lógica ceremonial es la lógica del intercambio" (1993: 184).

Es importante observar que este principio fundacional entre el santo patrono y la comunidad también conforma un campo social atravesado por las dos fuerzas opuestas que ya hemos discutido, en donde tanto el relato mítico como el ritual tradicional prescriben el "deber ser" y el "deber hacer", mientras las fuerzas sociales divergentes cuestionan el principio fundacional, pugnan por un abandono de la tradición, de la "religiosidad popular", y una conversión a la "modernidad".

\section{Ambivalencia cronotópica}

C'est dans le temps que se développe l'espace et une discontinuité temporelle renvoie à une continuité spatiale... Cette dialectique entre un monde ciclique et un continuum historique me paraît être la grande originalité de la pensée cosmologique des mayas qui leur permet de penser le mythe en termes historiques (Boccara, citado en Gorza, 2006a: 38).

Como hemos visto, el ritual de la fiesta patronal de San Andrés se encuentra vinculado íntimamente con la narrativa mitológica de la fundación del pueblo, y es en este sentido que considero una "irrupción" del cronotopo mitológico en el "presente histórico" de la fiesta. ${ }^{40}$ Así lo muestran diversas actividades rituales que aluden directamente al mito, como lo ilustran las ofrendas al santo, que rememoran el principio fundacional, las severas abstinencias practicadas por los alféreces a fin de conjurar el maleficio del mal tiempo, etcétera. De hecho, resultan de especial interés las observaciones de Gorza acerca de un fenómeno de "especularidad" entre la narrativa mitológica y las ceremonias que ocurren durante la fiesta patronal. Por un lado, la especularidad entre la procesión durante la fiesta y el recorrido mitológico de san Andrés. ${ }^{41}$ "La posición de los dioses que cargan el tiempo y lo llevan a través del espacio, es simétrica con aquella de la comunidad ritual que camina llevando su historia por las calles del pueblo" (Gorza, 2006a: 96). Por otro lado, el autor señala la presencia del "pacto" de origen, manifiesto en diversos rituales, como ocurre durante la construcción de una casa.

${ }^{40}$ En el mismo sentido, véase Alejos García (2017) para el caso de las relaciones cronotópicas en el ritual terapéutico maya.

41 "La narrativa de la fundación es especular con las ceremonias que celebran el recorrido del santo patrono... la procesión el día de la fiesta grande va de la casa de los alféreces al templo y viceversa, mientras los capitanetik recorren a caballo los perímetros sagrados de pueblo, deteniéndose en las cruces de encuentro, de protección o separación de los espacios restantes" (Gorza, 2006b: 95). En el mismo sentido, véase las analogías que encuentra Vapnarsky (2003) entre la narrativa mitológica, los recorridos rituales y las migraciones históricas de los mayas yucatecos de su estudio. 
El pacto establecido tiene que ser actualizado continuamente para que tenga valor. El ritual se renueva cada vez que se construye una casa. Se sacrifican aves y se entierra la sangre al centro de la vivienda, para que los habitantes no sean comidos por ésta (literalmente: sventa li mo taxti'van li nae, "para que la casa no devore a las personas") y no padezcan enfermedades. Se ofrecen a los dioses comida, aguardiente, velas, incienso y rezos (Gorza, 2006a: 73).

En el mismo sentido de la especularidad, el autor destaca la existencia de las deidades dobles, presente en la narrativa mitológica y en las imágenes al interior de la iglesia: "cada santo se desdobla, dando origen a dos estatuas: una identificada como mayor y otra como menor" (Gorza, 2006b: 96). "Cada santo tiene su doble, según el principio normativo del hermano mayor, bankilal, y del menor, ytzinal" (Gorza, 2006a: 56-57).

La presencia del cronotopo mitológico en el espacio-tiempo ordinario se encuentra documentada en otros estudios etnográficos de los Altos de Chiapas, como el efectuado por Pitarch, quien afirma que en Cancuc el relato de migración del santo patrono se ubica en el "tiempo antiguo", previo al surgimiento del sol, pero que en ciertas ocasiones irrumpe en el tiempo presente: "Este tiempo antiguo de vez en cuando implosiona, por así decir, en el tiempo actual. En Cancuc se cuentan 'sucesos' en los que se describe un encuentro casual con San Juan o con un avatar de éste" (Pitarch, 2006: 80). El autor ofrece la siguiente explicación teórica sobre este fenómeno:

Como sabemos, para adquirir existencia, los personajes requieren de una trama narrativa cuyo principio estructurador es la configuración temporal de la acción (Ricoeur, 1987:174), pero esa configuración temporal es sumamente débil en el caso de los relatos - escasos y narrativamente poco elaborados-, donde los santos aparecen en un tiempo que es prácticamente un lugar (Riceur, 1987: 86).

Otra observación de Pitarch con relación a la percepción tzeltal de lo que podríamos considerar un cronotopo mitológico de su identidad es aquella según la cual "en sus santos los indígenas no ven sólo su interior, están viendo también sus orígenes y su futuro. Son un reflejo de los tiempos remotos en que peregrinaron..." (Pitarch, 2006: 87).

Así pues, podemos afirmar la coexistencia de dos cronotopos en el contexto del ritual de la fiesta patronal: el mitológico, enunciado claramente en la narrativa, y el ordinario, en el que se desenvuelve la vida de los sanandreseros, y que se ve trastocada por el primero en el contexto festivo.

Sin embargo, debe reconocerse que más allá del plano de abstracción teórica, estos cronotopos coexisten en un campo de tensiones marcado por dos fuerzas divergentes, una que opera hacia el centro, hacia el canon mitológico, y la otra centrífuga, que pugna hacia el anticanon, hacia el cuestionamiento del orden y la seriedad propuestos por Pukuj en su orientación lúdica, alegre y "carnavalesca" de la fiesta. Estas fuerzas divergentes hacen que en la realidad etnográfica nos 
encontremos con un amplio rango de modalidades de vivencia espacio-temporal que se sitúan en medio de estos dos polos, como lo argumenta Bajtín respecto del lenguaje:

Pero las fuerzas centrípetas de la vida del lenguaje, encarnadas en el "lenguaje único", actúan dentro de un plurilingüismo efectivo... junto a las fuerzas centrípetas actúan constantemente las fuerzas centrífugas de la lengua, a la vez que la centralizacón ideológico-verbal, con la unificación se desarrolla ininterrumpidamente el proceso de descentralización y separación... En los altos círculos ideológicosociales oficiales, el problema de la centralización cultural, nacional, política, del mundo ideológico-verbal, en las capas bajas, en los escenarios de las barracas y ferias, suena el plurilingüismo de los payasos, la ridiculización de "lenguas" y dialectos, evoluciona la literaura del fabliau y de las comedias satíricas, de las canciones de calle, de los proverbios y los chistes (Bajtín, 1989: 89-90).

En este sentido, considero importante retomar la crítica planteada por Toledo Tello respecto a las etnografías de los santos patronos y sus fiestas, como temas recurrentes de la antropología en Chiapas, en las cuales se ha dejado de lado de manera sistemática los puntos de vista y vivencias de la población mestiza (2006: 157). Así, la autora plantea que las versiones antagónicas acerca de la fundación del pueblo (de Simojovel) reflejan relaciones conflictivas entre indígenas y mestizos, en una disputa por la legitimidad de ser originarios del pueblo (Toledo, 2006: 160). Estas disputas muestran las tensiones que ocurren en la "realidad concreta": el cambio, el tiempo irreversible, el suceso, la diversidad de puntos de vista, etcétera. Allí se enmarca el surgimiento de rituales nuevos, contrarios al ritual tradicional y aquellos otros que inauguran tiempos nuevos.

\section{Conclusiones}

El análisis del material etnográfico nos permite afirmar la existencia de un principio fundacional complejo que involucra al parentesco, la economía, la moral, la ética y la cosmología, así como las relaciones entre los humanos, entre estos y su deidad patronal y entre todos ellos y las entidades de su entorno territorial. De hecho, el concepto mismo de territorio se pone en cuestión, ya que, al parecer, la gente cuenta solamente con un derecho de posesión y usufructo, pues la tierra no les pertenece, sino que es propiedad de los "dueños". Pero este principio fundacional es justamente el centro de un debate contemporáneo al interior de la población acerca del reconocimiento del patrono como "padre", de la obligación de "ofrendarle", así como de la propiedad "legal" de la tierra.

De esta discusión se derivan otros temas teóricos interesantes. Uno de ellos consiste en el lugar fundamental de los sobreentendidos en la cultura. De hecho, uno de estos sobreentendidos es el principio fundacional contenido en la narrativa y puesto en práctica durante el evento festivo. La comprensión de los 
sobreentendidos, como bien ha planteado Voloshinov, es clave para el estudio de la cultura, pues ellos constituyen "el horizonte espacial y semántico compartido de los hablantes... Sólo aquello que nosotros los hablantes sabemos, vemos, amamos y reconocemos, en lo que estamos unidos, puede llegar a ser la parte sobreentendida de una enunciación" (Voloshinov, 1997: 115-116).

La compleja relación entre el relato mitológico y la ritualidad asociada es otro aspecto teórico relevante. En términos de Leach (1970), "ambos son parte de lo mismo". De acuerdo con Lotman (1996), podemos decir que la naturaleza de ambos es ser parte de una totalidad, la cual se ha desarticulado con la evolución de la cultura, pero conservan nexos de relación, aunque en cierto sentido aparecen ocultos, también sobreentendidos. El rito como la contraparte del mito, como su aspecto performativo. El ritual opera como una escenificación de la narrativa mitológica. Toda la fiesta, con sus diversos actos rituales, como las ofrendas, alabanzas, peregrinaciones, visitas, etcétera, son actos que "responden" dialógicamente a las acciones realizadas por el santo en el pasado a fin de fundar el pueblo de sus hijos pero también a los actos que el santo sigue realizando en el presente para mantener la existencia y bienestar de la comunidad.

Otro asunto de interés que destaca en el análisis son los isomorfismos ${ }^{42}$ que ocurren en diversos planos de la cultura. Así por ejemplo, el ritual activa un principio básico de relación social isomorfo a la relación entre padres e hijos. Lo que el santo hizo por sus hijos, se replica en el ritual como un acto de retribución. Los hijos honran y alimentan al santo y reciben de éste bienes equivalentes: un lugar para vivir, tierra para cultivar, protección de los peligros. Otro fenómeno de isomorfismo lo encuentro en los héroes dobles. Existen varios ejemplos de duplicación, de repetición de "lo mismo" en diferentes planos de la cultura, que merecen de un estudio específico.

Otro aspecto importante es el fenómeno de reversión cronotópica que ocurre durante el ritual, en el sentido de una "vuelta a los orígenes" una "refundación", o "rememoración" que ocurre con la emergencia del tiempo-espacio mítico, que transporta a los hijos al momento del origen, fundacional. En sentido inverso, otra "reversión" ocurre en los procesos de "abandono de la tradición" y "secularización de la vida" reportado por los antropólogos en las comunidades indígenas. Como hemos visto, esto nos lleva a la interrogante acerca del problema del cambio cultural, del abandono del principio fundacional enunciado en el mito y refrendado en el ritual. ¿Qué ocurre en una comunidad que pierde este principio, una comunidad que abandona, que reniega de sus mitos y sus ritos fundacionales? Considero que la respuesta se encuentra en que esa "reversión" cronotópica se enmarca en el fenómeno ya señalado por Bajtín en su discusión sobre la existencia de fuerzas contrarias que operan al interior de la cultura.

42 Para una referencia acerca de los isomorfismos en la cultura, véase Lotman (1996). 


\section{Agradecimientos}

Una versión preliminar del presente artículo fue presentada como ponencia en el X Congreso Internacional de Mayistas en 2016, en el marco de mi participación en el Grupo Internacional de Investigación (GDRI RITMO) del Centro Nacional de Investigación Científica de Francia (CNRS), "Crear, destruir, transformar las modalidades de las acciones rituales en Mesoamérica”. Agradezco a sus organizadores por la invitación a participar en este proyecto académico.

Agradezco a los dictaminadores de este artículo por sus atinados comentarios y a Marysol Alhim Rodríguez Maldonado por el cuidado de la edición.

\section{Bibliografía}

Alejos García, José

2012 "Enthymemes underlying Maya Mythical Narrative", Dialogues with Bakhtinian Theory: Proceedings of the Thirteenth International Mikhail Bakhtin Conference, pp. 395-405, M. Polyuha, C. Thomson y A. Wall (eds.). Canadá: Mastego Press.

2017 "Ïikin y kéex. Cronotopos del ritual terapéutico maya", Estudios de Cultura Maya, XLIX : 247-271.

Anónimo

1963 “Síntesis socio-económica del Departamento de Totonicapán”, Guatemala Indígena, 3 (2): 43-92.

Bajtín, Mijaíl

1981 "Forms of Time and of the Chronotope in the Novel", The Dialogic Imagination, pp. 84-258, Michael Holquist (ed.), Caryl Emerson y Michael Holquist (trads.). Austin: The University of Texas Press.

1989 Teoría y estética de la novela. Madrid: Taurus.

Gorza, Piero

2006a Habitar el tiempo en San Andrés Larráinzar. Paisajes indígenas de los Altos de Chiapas. México: Universidad Nacional Autónoma de México y Colegio de Michoacán.

2006b "Legítimos hombres, legítima tierra. Dinámicas simbólicas contradictorias en la construcción de fronteras", De la mano de lo sacro. Santos y demonios en el mundo maya, pp. 91-99, M. Ruz (ed.). México: Universidad Nacional Autónoma de México.

Hidalgo Pérez, Manuel

1985 Tradición oral de San Andrés Larráinzar: Algunas costumbres y relatos tzotziles. México: Gobierno del Estado de Chiapas. 
Holland, William

1961 "Tonalismo y nagualismo entre los indios tzotziles", Estudios de Cultura Maya, I: 167-183.

1963 Medicina maya en Los altos de Chiapas: un estudio del cambio sociocultural. México: Instituto Nacional Indigenista.

Leach, Edmund

1970 [1954] Political Systems of Highland Burma. Londres: The Athlone Press.

López González, Juan

2003 Peregrinación de nuestros antepasados. México: Consejo Estatal para la Cultura y las Artes de Chiapas.

Lotman, luri

1996 La semiosfera I. Semiótica de la cultura y del texto. Madrid: Ediciones Cátedra.

Millán, Saúl

1993 La ceremonia perpetua. México: Instituto Nacional Indigenista.

Navarrete, Federico

2004 “¿Dónde queda el pasado? Reflexiones sobre los cronotopos históricos”, El historiador frente a la historia. El tiempo en Mesoamérica, pp. 29-52, Virginia Guedea (coord.). México: Universidad Nacional Autónoma de México,

Ochiai, Kazuyazu

1983 "Viaje invernal de los antepasados: una comparación entre el Popol Vuh y la tradición oral de los tzotziles modernos en torno a la fundacióndel pueblo", Nuevas perspectivas sobre el Popol Vuh, pp. 331-341, R. Carmack y F. Morales Santos (eds.). Guatemala: Editorial Piedra Santa.

1985 Cuando los santos vienen marchando. Rituales públicos intercomunitarios tzotziles. San Cristóbal de las Casas: Universidad Autónma e Chiapas.

2006 "Visitas de santos en San Andrés Larráinzar", De la mano de lo sacro. Santos y demonios en el mundo maya, pp. 101-156, M. Ruz (ed.). México: Universidad Nacional Autónoma de México.

Pitarch, Pedro

2006 "Conjeturas sobre la identidad de los santos tzeltales", De la mano de lo sacro. Santos y demonios en el mundo maya, pp. 67-89, M. Ruz (ed.). México: Universidad Nacional Autónoma de México.

Ruiz, Lucas

2015 Nichimal k'op. Etnografía del discurso ritual en Larráinzar, tesis de doctorado en Estudios Mesoamericanos. México: Universidad Nacional Autónoma de México, Posgrado en Estudios Mesoamericanos, Facultad de Filosofía y Letras, Instituto de Investigaciones Filológicas.

Toledo Tello, Sonia

2006 “El santo patrón de Simojovel. Las disputas simbólicas entre la población indígena 
y 'mestiza”, De la mano de lo sacro. Santos y demonios en el mundo maya, pp. 157-176, M. Ruz (ed.). México: Universidad Nacional Autónoma de México.

Vapnarsky, Valentina

2003 "Recorridos instauradores: configuración y apropiación del espacio y del tiempo entre los mayas yucatecos”, Espacios mayas, pp. 363-381, A. Breton, A. Monod y M. Ruz (eds.). México: Universidad Nacional Autónoma de México y Centro de Estudios Mexicanos y Centroamericanos.

Voloshinov, Valentin

1997 "La palabra en la vida y la palabra en la poesía. Hacia una poética sociológica”, Hacia una filosofía del acto ético. De los borradores, pp. 106-137, M. Bajtín. Barcelona: Anthropos Editorial. 